\title{
Predictors of changes in adolescents' consumption of fruits, vegetables and energy-dense snacks
}

\author{
Natalie Pearson*, Kylie Ball and David Crawford \\ Centre for Physical Activity and Nutrition Research, School of Exercise and Nutrition Sciences, Deakin University, \\ Burwood, VIC 3125, Australia \\ (Received 19 May 2010 - Revised 16 August 2010 - Accepted 21 September 2010 - First published online 25 October 2010)
}

\section{Abstract}

Understanding the predictors of developmental changes in adolescent eating behaviours is important for the design of nutrition interventions. The present study examined associations between individual, social and physical environmental factors and changes in adolescent eating behaviours over 2 years. Consumption of fruits, vegetables and energy-dense snacks was assessed using a Web-based survey completed by 1850 adolescents from years 7 and 9 of secondary schools in Victoria, Australia, at baseline and 2 years later. Perceived value of healthy eating, self-efficacy for healthy eating, social modelling and support, and home availability and accessibility of foods were assessed at baseline. Self-efficacy for increasing fruit consumption was positively associated with the change in fruit and vegetable consumption, while self-efficacy for decreasing junk food consumption was inversely associated with the change in energy-dense snack consumption. Home availability of energy-dense foods was inversely associated with the change in fruit consumption and positively associated with the change in energy-dense snack consumption, while home availability of fruits and vegetables was positively associated with the change in vegetable consumption. Perceived value of healthy eating and modelling of healthy eating by mothers were positively associated with the change in fruit consumption. Support of best friends for healthy eating was positively associated with the change in vegetable consumption. Self-efficacy and home availability of foods appear to be consistent predictors of change in fruit, vegetable and energy-dense snack consumption. Future study should assess the effectiveness of methods to increase self-efficacy for healthy eating and to improve home availability of healthy food options in programmes promoting healthy eating among adolescents.

Key words: Fruit: Vegetables: Energy-dense snacks: Adolescents: Determinants: Longitudinal studies

Nutrition has come to the fore as one of the major modifiable determinants of chronic disease ${ }^{(1)}$. Establishing healthy eating habits during adolescence is important given that eating behaviours likely to cause fatness are actively adopted during this age ${ }^{(2)}$, while fruit and vegetable consumption, which has both immediate and longterm health-protective benefits ${ }^{(3,4)}$, has been shown to decline $^{(5)}$. Furthermore, eating behaviours and habits established during adolescence are likely to persist into adulthood $^{(6,7)}$. To prevent the development of chronic conditions, decreasing the consumption of energy-dense foods and increasing the consumption of fruits and vegetables during adolescence are important targets for nutrition interventions. The development of effective nutrition interventions requires a detailed understanding of the determinants of target eating behaviours. More specifically, knowledge about the determinants of developmental change in target eating behaviours during key life stages such as adolescence is required ${ }^{(8)}$.
Many potential determinants of adolescent eating behaviours have been identified primarily from cross-sectional studies $^{(9-11)}$. For example, review-level evidence has shown that individual factors such as preferences, attitude, self-efficacy and intentions are associated with fruit, vegetable and energy-dense food consumption ${ }^{(9,12)}$. In addition, perceived modelling of eating behaviours, parental intake and home availability of foods are the socio-environmental determinants best supported by the literature in association with fruit, vegetable and energy-dense food consumption among adolescents ${ }^{(9,11,12)}$. However, few studies have examined the determinants of developmental changes in adolescent eating behaviours over time ${ }^{(13-15)}$, with existing studies being limited to the examination of change in fruit and vegetable and soft drink consumption. For example, changes in fruit and vegetable accessibility at home, accessibility at school, preferences and awareness of fruit and vegetable recommendations have been associated with an increase in fruit and vegetable

Abbreviations: T1, baseline; T2, follow-up; YEP, Youth Eating Patterns.

*Corresponding author: N. Pearson, fax +6139244 6017, email natalie.pearson@deakin.edu.au 
consumption over 12 months $^{(14)}$. High perceived behavioural control to decrease soft drink consumption, low availability of soft drinks and stricter family food rules were associated with decreases in consumption of soft drinks over 4 months ${ }^{(15)}$. Studies are now needed that investigate potential individual, social and physical environmental factors together as potential determinants of change in a range of adolescent eating behaviours over a longer time frame.

Given the importance of explicit theoretical foundations for the effectiveness of behavioural change interventions ${ }^{(16)}$, and more specifically, nutrition interventions ${ }^{(17,18)}$, behavioural theories should be utilised to provide a framework for studying key factors associated with changes in eating behaviours. Recent study support the use of social-ecological models in understanding eating behaviours ${ }^{(19,20)}$, as well as other health behaviours (e.g. physical activity and sedentary behaviours) ${ }^{(21,22)}$ and health outcomes (e.g. obesity) ${ }^{(20)}$. Social-ecological models differ from other behavioural models (e.g. theory of planned behaviour) in that they give broader consideration to the contextual factors relative to the individual. Social-ecological models posit that factors at the individual (e.g. self-efficacy), social (social support) and physical (e.g. availability and accessibility) environmental levels interact to influence health behaviour ${ }^{(23,24)}$. To our knowledge, no previous studies have examined individual, social and physical environmental determinants of developmental change in consumption of fruits, vegetables and energydense snacks among Australian adolescents. Using a social-ecological framework, the present study aimed to understand individual, social and physical environmental predictors of changes in adolescents' consumption of fruits, vegetables and energy-dense snacks over a 2-year period.

\section{Methods}

\section{Study procedure}

The Youth Eating Patterns (YEP) study is a longitudinal study of dietary habits among adolescents in Melbourne, Australia. All co-educational state (government) and Catholic secondary schools (years 7-12) with enrolments over 200 , located in the southern metropolitan region of Melbourne and the non-metropolitan region of Gippsland, to the east of Melbourne, were invited to participate in the study. Of the seventy schools (forty-seven metropolitan and twenty-three non-metropolitan) that met these criteria, thirty-seven (twenty metropolitan and seventeen nonmetropolitan) agreed to participate. The YEP survey is an online food habits survey and was administered by teachers during a class when students had access to computers. The survey was administered during 2004 and 2005 (baseline, T1) and again 2 years later in 2006 and 2007 (follow-up, T2). The study procedures were approved by the Ethics Committee of Deakin University and the Victorian Department of Education and Training and the Catholic Education Office. A detailed description of the YEP survey, participant recruitment and study procedures has been described in previous publications ${ }^{(25,26)}$.

\section{Participants}

All students ( $n$ 9842) from year 7 (aged $12-13$ years) and year 9 (aged 14-15 years) from the participating schools were invited to complete the online survey at baseline. Teachers distributed parental consent forms via students asking permission for their child to participate in the study. The consent form also asked parents to provide information about their family circumstances (e.g. marital status, education level, employment status, number of children). Parental consent was obtained for 4502 (46\%) of all eligible students. Online surveys were completed at baseline by 3264 adolescents. Of these, 1884 (58\%) completed the YEP survey at the 2-year follow-up.

The present analyses are based on the subset of 1850 adolescents who had non-missing data for all the variables examined in the present study (i.e. T1 data for eating behaviours, cognitive and environmental predictors and $\mathrm{T} 2$ data for eating behaviours). Comparison of these 1850 adolescents with those who were not followed up ( $n$ 1380) showed no significant differences in the consumption of energy-dense snacks, fruits and vegetables. However, a significantly $(P<0.05)$ higher proportion of adolescents who were followed up, compared with those who were not, were girls (55.4\% compared with $44.6 \%$ ) and were in year 7 at baseline $(65 \cdot 2 \%$ compared with $38 \cdot 4 \%)$.

\section{Measures}

The YEP survey collected information on demographic characteristics of adolescents including date of birth, school year and sex at T1.

\section{Adolescent eating behaviours}

Consistent with other large-scale studies of dietary intake and eating behaviours of adolescents ${ }^{(27)}$, food intake was assessed at baseline (T1) and follow-up (T2) using an FFQ. This FFQ was based on previously validated indices of food intake ${ }^{(28)}$ and is described in detail in previous publications ${ }^{(25,26)}$. Respondents indicated how frequently they had consumed thirty-seven food items during the previous month. Seven response categories ranged from 'never or not in the last month' to 'several times a day'.

The present analyses are based on a subset of six food items from the FFQ completed at T1 and T2, which were categorised into three food groups: fruits; vegetables; energy-dense snacks. These indicators were selected due to their importance in contributing to the healthfulness of overall diet. The frequency of consumption of the six 
food items in the past month was converted to a daily equivalent, which is an established method ${ }^{(29)}$ that has been used in other dietary studies ${ }^{(27,30)}$. Daily equivalent scores at T1 and T2 were calculated as follows: not in the last month ( 0.00 per $d)$; several times per month $(0.11$ per $\mathrm{d})$; once a week $(0.14$ per $\mathrm{d})$; a few times a week $(0.36$ per $d)$; on most days $(0.71$ per $d)$; once per day ( 1.00 per $d)$; several times per day ( 2.50 per $d)$. The daily intake for each of the three food groups was calculated by summing the daily equivalence for the food items in each food group. The estimated daily intake of the energy-dense snack group included the summed equivalence of four items (confectionery, cakes, sweet biscuits and potato crisps/salty snacks). The daily intake of fruits included fruits as one item (fresh, canned, frozen or dried), and the daily intake of vegetables included vegetables as one item.

\section{Individual, social and physical environmental factors}

Two questions, developed specifically for the present study, assessed the perceived value (importance) of eating healthy foods and limiting the amount of junk food consumed at T1. Responses were marked on a fourpoint Likert scale, ranging from (1) not at all important to (4) very important, and summed (Cronbach's $\alpha=0.70$ ).

Adolescents were asked three questions about their confidence in cutting down on 'junk food' (i.e. food that is low in nutritional value and typically high in energy) at T1: 'If you wanted to, about how confident (sure) are you that you could cut down on junk food when you're hanging out with friends'; '.. at school'; '.. at home'. They were also asked three questions regarding confidence in eating more fruits in the same situations at T1. Response options were given on a four-point Likert scale, ranging from (1) not at all confident to (4) very confident. Responses were summed separately to provide two self-efficacy scores, one for cutting down on junk food (Cronbach's $\alpha=0 \cdot 81$ ) and one for increasing fruit consumption (Cronbach's $\alpha=0 \cdot 84$ ).

Perceived modelling of the eating behaviour of two key persons (best friend and mother) was assessed with items developed specifically for the present study at T1. For each, the adolescent provided a rating of their agreement with four separate statements: my best friend/mother eats healthy food; limits junk foods; eats vegetables most days; eats fruits most days (ranging from (1) disagree to (3) agree). Two variables were created by summing the responses to the four items (Cronbach's $\alpha=0.77$ for perceived modelling of healthy eating by best friend and Cronbach's $\alpha=0.71$ for perceived modelling of healthy eating by mother). In addition, perceived social support of friends and family was assessed with items adapted from Sallis et $a l^{(31)}$ at T1. For each, the adolescent provided a rating of their agreement (ranging from (1) never/rarely to (3) often) with four separate statements: whether friends/family make you feel good about what you eat; eat healthy food with you; discourage you from eating junk food; encourage you to eat healthy food. Two variables were created by summing the responses to the four items (Cronbach's $\alpha=0.77$ for perceived support for healthy eating by best friend and Cronbach's $\alpha=0.71$ for perceived support for healthy eating by family).

Perceived availability of different foods within the home environment (environmental predictor) was assessed with items adapted from the Project EAT ${ }^{(27)}$ at T1. Respondents were asked how frequently (ranging from (1) never/rarely to (4) always) the following items were available within the home: fruits; vegetables; cakes or sweet biscuits; potato crisps or salty snacks; chocolate or lollies. The frequency of availability of fruit and vegetable items was summed (Cronbach's $\alpha=0.74$ ), as were the frequencies of the energy-dense snack items (Cronbach's $\alpha=0 \cdot 81$ ). Accessibility of places to buy fast foods and places to buy snacks near to where adolescents live was assessed with items developed specifically for the present study at T1. For each, the adolescents provided a rating of the accessibility of such places, ranging from (1) none/don't know to (3) a lot. Responses for the two items were then summed (Cronbach's $\alpha=0.74$ ).

\section{Statistical analysis}

All analyses were conducted using the SPSS statistical software package version 17.0 (SPSS Inc., Chicago, IL, USA). Descriptive statistics were used to summarise the demographic and eating characteristics of the sample. Independent $t$ tests were conducted to determine sex and year-level differences in predictor and outcome variables. Pearson's correlation was used to assess correlations $(r)$ between the baseline (T1) and follow-up (T2) eating behaviours.

Bivariate linear regression analyses (model 1) were conducted to examine associations between the proposed individual, social and physical environmental factors and the changes in the eating behaviours of interest. All predictor factors that were significantly associated with the change in eating behaviour in the bivariate analyses were entered into multiple linear regression models (model 2). In each model, T2 eating behaviour was entered as the dependent variable, and T1 eating behaviour was entered as a covariate to allow for a prediction of the change in behaviour over the 2 -year period ${ }^{(15,32)}$. This method corrects for the phenomenon of regression to the mean. The consequence of regression to the mean is that, by chance, the change between baseline and follow-up is related to the initial value ${ }^{(32)}$. Given that all eating behaviours at baseline were significantly associated with their respective eating behaviour at follow-up (fruit consumption $r 0.38 \quad(P<0.01)$; vegetable consumption $r \quad 0.28$ $(P<0.01)$; energy-dense snack consumption $r \quad 0.40$ $(P<0.01)$ ), this method of examining the predictors of 
change was deemed appropriate. In the following sections, follow-up eating behaviour corrected for baseline eating behaviour is classified as 'change' in eating behaviour. All regression models were adjusted for sex and age (year level) of adolescents.

\section{Results}

The majority of the adolescent sample at baseline were girls $(55 \%)$ and in year $7(65 \%)$. The mean age of adolescents was 13.2 (SD 1.6) years. Individual, social and physical environmental variables (T1) and eating behaviours at baseline (T1) and follow-up (T2) are described in Table 1 according to sex and year level. Females had significantly higher perceived values for healthy eating and higher self-efficacy for increasing fruit consumption than males. Females also reported higher perceived modelling for healthy eating by best friend, higher levels of support for healthy eating by best friend and family and higher perceived availability of fruits and vegetables at home than males. Females reported higher intakes of fruits (serves/d) at baseline and follow-up and higher intakes of vegetables at follow-up than males. Males reported higher perceived availability of energy-dense snack foods at home and higher intakes of energy-dense snacks (serves/d) at follow-up than females.

Participants in year 7 at baseline had significantly higher perceived values for healthy eating and reported higher perceived modelling for healthy eating by best friend, higher levels of support for healthy eating by best friend and family and higher perceived availability of fruits and vegetables and energy-dense snack foods at home than participants in year 9 at baseline. Furthermore, those in year 7 had higher intakes of vegetables (serves/d) at baseline and follow-up and higher intakes of energy-dense snacks (serves/d) at follow-up than those in year 9 at baseline.

Tables 2-4 show the results of the bivariate and multiple linear regression analyses on changes in fruit, vegetable and energy-dense snack consumption, respectively. After adjusting for baseline fruit consumption, sex and year level, seven variables were associated with changes in fruit consumption (model 1, Table 2). After adjusting for all significant variables from model 1 , only four variables remained significant (model 2). Values for healthy eating, self-efficacy for increasing fruit consumption and modelling of healthy eating by mother were associated with positive changes in fruit consumption. Perceived home availability of energy-dense snack foods was associated with negative changes in fruit consumption. These variables accounted for $19 \%$ of the variance in the change in fruit consumption.

After adjusting for baseline vegetable consumption, sex and year level, seven variables were associated with changes in vegetable consumption (model 1, Table 3). After adjusting for all significant variables from model 1 ,

Table 1. Description of individual, social and physical environmental variables at baseline (2004-5) and eating behaviours at baseline and follow-up by sex and year level of adolescent participants $(n$ 1850) $\ddagger$

(Mean values and standard deviations)

\begin{tabular}{|c|c|c|c|c|c|c|c|c|}
\hline & \multicolumn{2}{|c|}{$\begin{array}{l}\text { Males } \\
(n \text { 828) }\end{array}$} & \multicolumn{2}{|c|}{$\begin{array}{l}\text { Females } \\
(n \text { 1032) }\end{array}$} & \multicolumn{2}{|c|}{$\begin{array}{c}\text { Year } 7 \\
(n 1202)\end{array}$} & \multicolumn{2}{|c|}{$\begin{array}{l}\text { Year } 9 \\
(n 648)\end{array}$} \\
\hline & Mean & SD & Mean & SD & Mean & SD & Mean & SD \\
\hline \multicolumn{9}{|l|}{ Individual } \\
\hline Value of healthy eating (range $2-8$ ) & 5.99 & 1.49 & $6 \cdot 18^{\star \star}$ & 1.37 & $6 \cdot 26$ & 1.34 & $5 \cdot 79 \dagger+\dagger$ & 1.52 \\
\hline Self-efficacy for increasing fruit (range 3-12) & 8.96 & $2 \cdot 61$ & $9.56^{\star \star \star}$ & $2 \cdot 23$ & 9.37 & 2.43 & $9 \cdot 15$ & $2 \cdot 41$ \\
\hline Self-efficacy for decreasing junk food (range 3-12) & 8.57 & 2.51 & $8 \cdot 77$ & $2 \cdot 18$ & 8.73 & $2 \cdot 36$ & $8 \cdot 60$ & $2 \cdot 28$ \\
\hline \multicolumn{9}{|l|}{ Social environment } \\
\hline Perceived modelling of healthy eating by best friend (range $4-12$ ) & 8.88 & $2 \cdot 14$ & $9 \cdot 38^{\star \star \star}$ & $2 \cdot 14$ & $9 \cdot 31$ & 2.09 & $8 \cdot 86+1 \dagger$ & $2 \cdot 22$ \\
\hline Perceived modelling of healthy eating by mother (range $4-12$ ) & 11.09 & 1.54 & $11 \cdot 15$ & $1 \cdot 31$ & $11 \cdot 16$ & 1.36 & 11.05 & 1.52 \\
\hline Perceived support of best friend for healthy eating (range $4-12$ ) & 6.41 & $2 \cdot 21$ & $7 \cdot 14^{\star \star \star}$ & 2.08 & 6.97 & $2 \cdot 20$ & $6 \cdot 52+\dagger \dagger$ & 2.07 \\
\hline Perceived support of family for healthy eating (range $4-12$ ) & 9.00 & $2 \cdot 12$ & $9 \cdot 56^{\star \star *}$ & 1.87 & 9.47 & 1.99 & 9.00††† & 2.04 \\
\hline \multicolumn{9}{|l|}{ Physical environment } \\
\hline Home availability of fruits and vegetables (range 2-8) & 7.44 & $1 \cdot 13$ & $7.59^{* \star *}$ & 0.91 & 7.56 & 0.97 & $7.46 \dagger$ & 1.09 \\
\hline Home availability of energy-dense snack foods (range $3-12$ ) & $7 \cdot 66$ & $2 \cdot 14$ & $7 \cdot 42^{\star \star}$ & 1.91 & 7.44 & 1.98 & $7 \cdot 68 \dagger$ & $2 \cdot 08$ \\
\hline Accessibility of places to buy unhealthy foods close to home (range 2-8) & 3.91 & 1.21 & 3.97 & $1 \cdot 16$ & 3.89 & 1.18 & $4.03 \dagger$ & $1 \cdot 19$ \\
\hline \multicolumn{9}{|l|}{ Eating behaviours } \\
\hline \multicolumn{9}{|l|}{ Fruit serves/d } \\
\hline Baseline (T1) & 0.84 & 0.84 & $0.98^{\star \star \star}$ & 0.85 & 0.94 & 0.86 & 0.87 & 0.83 \\
\hline Follow-up (T2) & 0.84 & 0.83 & $1 \cdot 10^{\star \star \star}$ & 0.90 & 1.01 & 0.88 & 0.93 & 0.88 \\
\hline \multicolumn{9}{|l|}{ Vegetable serves/d } \\
\hline Baseline (T1) & 0.75 & 0.67 & 0.73 & 0.62 & 0.78 & 0.65 & $0.68+t \dagger$ & 0.60 \\
\hline Follow-up (T2) & 0.66 & 0.54 & $0.76^{\star \star *}$ & 0.57 & 0.74 & 0.58 & $0.65+\dagger \dagger$ & 0.52 \\
\hline \multicolumn{9}{|l|}{ Energy-dense snack serves/d } \\
\hline Baseline (T1) & 1.26 & 1.56 & $1 \cdot 19$ & 1.32 & 1.22 & 1.42 & 1.22 & 1.46 \\
\hline Follow-up (T2) & $1 \cdot 10$ & 1.35 & $0.99^{*}$ & $1 \cdot 11$ & 1.08 & 1.27 & $0.96 \dagger$ & $1 \cdot 12$ \\
\hline
\end{tabular}

Mean values were significantly different from those of males: ${ }^{*} P<0.05$; ${ }^{\star \star} P<0.01$; ${ }^{\star \star \star} P<0.001$.

Mean values were significantly different from the adolescents in year $7: \dagger P<0.05 ; \dagger \dagger \dagger P<0.001$

‡ One-way ANOVA for differences by sex and year level. 
Table 2. Results of bivariate and multiple linear regression analyses: individual, social and physical environmental variables and (model 1) T2 fruit serves/d adjusted for T1 fruit serves/d, sex and school year; (model 2) T2 fruit serves/d adjusted for T1 fruit serves/d, sex, school year and all variables significant in the bivariate linear regression analyses

(Unstandardised regression coefficients and $95 \%$ confidence intervals)

\begin{tabular}{|c|c|c|c|c|c|c|}
\hline & \multicolumn{3}{|c|}{ T2 fruit (serves/d) model $1^{*}$} & \multicolumn{3}{|c|}{ T2 fruit (serves/d) model $2 \dagger$} \\
\hline & $\begin{array}{l}\text { Unstandardised } \\
\text { regression } \\
\text { coefficient }\end{array}$ & $95 \% \mathrm{Cl}$ & $P$ & $\begin{array}{l}\text { Unstandardised } \\
\text { regression } \\
\text { coefficient }\end{array}$ & $95 \% \mathrm{Cl}$ & $P$ \\
\hline \multicolumn{7}{|l|}{ Individual } \\
\hline Value of healthy eating & 0.07 & $0.04,0.090$ & $<0.001$ & 0.03 & $-0.001,0.06$ & 0.050 \\
\hline Self-efficacy for increasing fruit & 0.04 & $0.02,0.06$ & $<0.001$ & 0.02 & $0.004,0.05$ & 0.021 \\
\hline Self-efficacy for decreasing junk food & 0.03 & $0.01,0.04$ & 0.002 & -0.01 & $-0.03,0.01$ & 0.399 \\
\hline \multicolumn{7}{|l|}{ Social environment } \\
\hline Modelling of healthy eating by best friend & 0.02 & $-0.001,0.03$ & 0.068 & & & \\
\hline Modelling of healthy eating by mother & 0.07 & $0.05,0.09$ & $<0.001$ & 0.06 & $0.03,0.09$ & $<0.001$ \\
\hline Support of best friend for healthy eating & 0.03 & $0.01,0.05$ & $<0.001$ & 0.01 & $-0.01,0.03$ & 0.289 \\
\hline Support of family for healthy eating & 0.04 & $0.02,0.06$ & $<0.001$ & 0.01 & $-0.01,0.03$ & 0.317 \\
\hline \multicolumn{7}{|l|}{ Physical environment } \\
\hline $\begin{array}{l}\text { Home availability of fruits and vegetables } \\
\text { Home availability of energy-dense snack foods }\end{array}$ & $\begin{array}{r}0.02 \\
-0.04\end{array}$ & $\begin{array}{l}-0.02,0.06 \\
-0.06,-0.02\end{array}$ & $\begin{array}{r}0.259 \\
<0.001\end{array}$ & -0.03 & $-0.05,-0.01$ & 0.011 \\
\hline $\begin{array}{l}\text { Accessibility of places to buy fast foods } \\
\text { and snacks close to home }\end{array}$ & -0.002 & $-0.03,0.03$ & 0.877 & & & \\
\hline
\end{tabular}

T1, baseline; T2, follow-up.

* Model 1: adjusted for sex, year level and baseline fruit intake.

† Model 2: adjusted for sex, year level, baseline fruit intake and all significant predictor variables from model 1.

only three variables remained significant (model 2). Selfefficacy for increasing fruit consumption, support for healthy eating by best friend and perceived home availability of fruit and vegetables were associated with positive changes in vegetable consumption. These variables accounted for $10 \%$ of the variance in the change in vegetable consumption.

After adjusting for baseline energy-dense snack consumption, sex and year level, four variables were associated with changes in energy-dense snack consumption (model 1, Table 4). After adjusting for all significant variables from model 1 , only two variables remained significant (model 2). Self-efficacy for decreasing junk food consumption was negatively associated with changes in energy-dense snack consumption. Perceived home availability of energy-dense snack foods was positively associated with changes in energy-dense snack consumption. These two variables accounted for $19 \%$ of the variance in the change in energy-dense snack consumption.

\section{Discussion}

Little is known about the predictors of developmental change in adolescent dietary behaviours, yet such

Table 3. Results of bivariate and multiple linear regression analyses: individual, social and physical environmental variables and (model 1) T2 vegetable serves/d adjusted for T1 vegetable serves/d, sex and school year; (model 2) T2 vegetable serves/d adjusted for T1 vegetable serves/d, sex, school year and all variables significant in the bivariate linear regression analyses

(Unstandardised regression coefficients and $95 \%$ confidence intervals)

\begin{tabular}{|c|c|c|c|c|c|c|}
\hline & \multicolumn{3}{|c|}{ T2 vegetable (serves/d) model $1^{*}$} & \multicolumn{3}{|c|}{ T2 vegetable (serves/d) model $2 \dagger$} \\
\hline & $\begin{array}{l}\text { Unstandardised } \\
\text { regression } \\
\text { coefficient }\end{array}$ & $95 \% \mathrm{Cl}$ & $P$ & $\begin{array}{l}\text { Unstandardised } \\
\text { regression } \\
\text { coefficient }\end{array}$ & $95 \% \mathrm{Cl}$ & $P$ \\
\hline \multicolumn{7}{|l|}{ Individual cognitions } \\
\hline Value of healthy eating & 0.03 & $0.02,0.05$ & $<0.001$ & 0.01 & $-0.01,0.03$ & 0.275 \\
\hline Self-efficacy for increasing fruit & 0.03 & $0.02,0.04$ & $<0.001$ & 0.02 & $0.003,0.03$ & 0.017 \\
\hline Self-efficacy for decreasing junk food & 0.02 & $0.01,0.03$ & $<0.001$ & 0.001 & $-0.01,0.01$ & 0.928 \\
\hline \multicolumn{7}{|l|}{ Social environment } \\
\hline Modelling of healthy eating by best friend & 0.01 & $-0.002,0.02$ & $0 \cdot 100$ & & & \\
\hline Modelling of healthy eating by mother & 0.01 & $-0.01,0.02$ & 0.490 & & & \\
\hline Support of best friend for healthy eating & 0.02 & $0.01,0.03$ & 0.001 & 0.01 & $0.001,0.03$ & 0.029 \\
\hline Support of family for healthy eating & 0.02 & $0.004,0.03$ & 0.009 & 0.001 & $-0.01,0.02$ & 0.847 \\
\hline \multicolumn{7}{|l|}{ Physical environment } \\
\hline Home availability of fruits and vegetables & 0.04 & $0.01,0.07$ & 0.003 & 0.03 & $0.001,0.05$ & 0.042 \\
\hline Home availability of energy-dense snack foods & -0.02 & $-0.03,-0.01$ & 0.004 & -0.01 & $-0.03,0.001$ & 0.066 \\
\hline $\begin{array}{l}\text { Accessibility of places to buy fast foods and } \\
\text { snacks close to home }\end{array}$ & -0.01 & $-0.03,0.01$ & $0 \cdot 184$ & & & \\
\hline
\end{tabular}

T1, baseline; T2, follow-up.

${ }^{*}$ Model 1: adjusted for sex, year level and baseline vegetable intake.

† Model 2: adjusted for sex, year level, baseline vegetable intake and all significant predictor variables from model 1. 
Table 4. Results of bivariate and multiple linear regression analyses: individual, social and physical environmental variables and (model 1) T2 energydense snack serves/d adjusted for T1 energy-dense serves/d, sex and school year; (model 2) T2 energy-dense serves/d adjusted for T1 energy-dense serves/d, sex, school year and all variables significant in the bivariate linear regression analyses

(Unstandardised regression coefficients and $95 \%$ confidence intervals)

\begin{tabular}{|c|c|c|c|c|c|c|}
\hline & \multicolumn{3}{|c|}{ T2 energy-dense snack (serves/d) model $1^{*}$} & \multicolumn{3}{|c|}{ T2 energy-dense snack (serves/d) model $2 \dagger$} \\
\hline & $\begin{array}{l}\text { Unstandardised } \\
\text { regression } \\
\text { coefficient }\end{array}$ & $95 \% \mathrm{Cl}$ & $P$ & $\begin{array}{l}\text { Unstandardised } \\
\text { regression } \\
\text { coefficient }\end{array}$ & $95 \% \mathrm{Cl}$ & $P$ \\
\hline \multicolumn{7}{|l|}{ Individual cognitions } \\
\hline Value of healthy eating & -0.07 & $-0.11,-0.03$ & $<0.001$ & -0.03 & $-0.07,0.01$ & $0 \cdot 181$ \\
\hline Self-efficacy for increasing fruit & -0.04 & $-0.06,-0.02$ & 0.001 & -0.01 & $-0.03,0.02$ & 0.604 \\
\hline Self-efficacy for decreasing junk food & -0.06 & $-0.08,-0.03$ & $<0.001$ & -0.03 & $-0.06,-0.002$ & 0.037 \\
\hline \multicolumn{7}{|l|}{ Social environment } \\
\hline Modelling of healthy eating by best friend & -0.01 & $-0.04,0.01$ & 0.275 & & & \\
\hline Modelling of healthy eating by mother & 0.02 & $-0.01,0.06$ & 0.204 & & & \\
\hline Support of best friend for healthy eating & -0.01 & $-0.04,0.01$ & 0.325 & & & \\
\hline Support of family for healthy eating & -0.01 & $-0.03,0.02$ & 0.801 & & & \\
\hline \multicolumn{7}{|l|}{ Physical environment } \\
\hline Home availability of fruits and vegetables & 0.01 & $-0.04,0.07$ & 0.640 & & & \\
\hline Home availability of energy-dense snack foods & 0.09 & $0.06,0.12$ & $<0.001$ & 0.08 & $0.05,0.12$ & $<0.001$ \\
\hline $\begin{array}{l}\text { Accessibility of places to buy fast foods } \\
\text { and snacks close to home }\end{array}$ & 0.03 & $-0.01,0.07$ & 0.167 & & & \\
\hline
\end{tabular}

T1, baseline; T2, follow-up.

* Model 1: adjusted for sex, year level and baseline energy-dense snack intake.

† Model 2: adjusted for sex, year level, baseline energy-dense snack intake and all significant predictor variables from model 1.

information is important for the design of nutrition interventions. The present study is one of the first to examine the associations between factors from individual, social and physical environmental domains and the change in fruit, vegetable and energy-dense snack consumption over 2 years. Self-efficacy and perceived home availability of foods were consistent predictors of change in all three of the dietary behaviours assessed. Evidence suggests that different foods are encoded with different meanings (e.g. comfort, pleasure, boredom, upset and relief) ${ }^{(33)}$ and moods ${ }^{(34)}$, are often consumed in different environments (e.g. alone at home, family meals, eating out and on the go), and their consumption may be influenced by different factors ${ }^{(35,36)}$. Identifying eating behaviours that 'share' determinants is important for the design of nutritionfocused interventions. Interventions targeting the change in multiple eating behaviours offer the potential of increased health benefits, maximised health promotion and reduced costs.

Sex and age differences were seen in individual, social and environmental variables as well as in adolescent eating behaviours. Girls and younger students consistently reported higher scores on more positive variables, compared with boys and year 9 students. For example, girls and year 7 students reported higher scores on values for healthy eating, support for healthy eating by best friend and family, home availability of fruits and vegetables, consumption of fruits and vegetables, and reported lower consumption of energy-dense snacks. Such findings are consistent with previous studies ${ }^{(12,37-39)}$ and suggest that interventions aimed at promoting healthy eating among adolescents should be sex and age specific.
Findings from the multivariable models in the present study suggested that self-efficacy was a consistent predictor of the change in adolescent eating behaviours. Several cross-sectional studies have shown a positive association between self-efficacy and fruit and vegetable consumption in adolescents ${ }^{(12,40,41)}$. Findings from the present study support and add to previous longitudinal studies ${ }^{(14)}$ by showing that adolescents in Australia who have high selfefficacy for increasing fruit consumption are more likely to positively change their fruit consumption over time. Self-efficacy for increasing fruit consumption was also positively associated with changes in vegetable consumption. It is possible that a higher self-efficacy for increasing fruit consumption is indicative of a higher self-efficacy for healthy eating. High self-efficacy for increasing fruit consumption might increase the likelihood of intending to adopt healthier eating behaviours, and intentions, according to the theory of planned behaviour ${ }^{(42)}$, are a pre-requisite to behavioural change ${ }^{(43)}$. Such pathways have not been tested previously with regard to adolescent self-efficacy for healthy eating but could provide insight into possible strategies for nutrition interventions.

Previous cross-sectional research has shown that selfefficacy for making healthy food choices is associated with lower energy-dense snack consumption ${ }^{(44)}$. Findings of the present study corroborate and extend such research by showing that adolescents who have high self-efficacy for decreasing junk food consumption are more likely to decrease their consumption of energy-dense snacks over time. Self-efficacy is a social cognition that reflects individuals' judgements of their capabilities to organise and execute courses of action required to attain designated types 
of performances ${ }^{(45)}$. Little is known about why some adolescents report higher levels of self-efficacy for healthy eating than others. A study on child socialisation suggests that the quality of parent-child interactions is significantly related to the development of adolescent self-efficacy ${ }^{(46)}$. Bandura $^{(47)}$ suggests that people's beliefs concerning their efficacy can be developed by four main forms of influence including mastery experiences (experiences of success/failure), vicarious experiences (provided by social models), social persuasion (verbal persuasion) and their physiological and emotional states (perception and interpretation of emotional and physical reactions). The consistency of the present findings regarding self-efficacy as a predictor of the change in adolescent eating behaviours suggests that this cognitive construct warrants further investigation in the domain of adolescent nutrition. An increased understanding of the determinants of selfefficacy for healthy eating in adolescents could inform interventions to promote self-efficacy in an effort to improve a range of eating behaviours among adolescents.

Individual behavioural change is difficult to achieve without addressing the context in which people make decisions ${ }^{(48)}$. Adolescents may have the confidence and belief that they are able to increase the consumption of healthy foods, but if the environment is not supportive (e.g. low access and availability of healthy food options), making healthy choices may then be difficult ${ }^{(48)}$. Several cross-sectional studies have shown a positive association between home availability of fruits and vegetables and adolescent consumption of fruits and vegetables ${ }^{(12,27,41)}$, and a positive association between home availability of unhealthy foods and consumption of fast foods ${ }^{(49)}$. In addition, low home availability of soft drinks has been associated with decreases in adolescent soft drink consumption over a 4-month period ${ }^{(15)}$. To the best of our knowledge, there are no studies examining the association between home availability of healthy and unhealthy foods and the change in adolescent eating behaviours over time. The present study advances previous findings by demonstrating that perceived home availability of fruits and vegetables is positively associated with the change in vegetable consumption, and that perceived home availability of energy-dense foods is negatively associated with the change in fruit consumption and positively associated with the change in energy-dense snack consumption. The present findings suggest that readily available foods within the home are likely to influence dietary intake among adolescents. Given that more than two-thirds of the foods that young people consume are from the home ${ }^{(50)}$, the effectiveness of methods for increasing home availability of healthy food options and for decreasing home availability of unhealthy foods should be tested.

In addition to self-efficacy and perceived home availability, modelling of healthy eating by the adolescent's mother was positively associated with the change in fruit consumption. Parental modelling of healthy eating has been associated with adolescent fruit consumption in a cross-sectional study ${ }^{(40)}$ and with the change in children's fruit and vegetable consumption in longitudinal research $^{(14)}$. Even though adolescents become more autonomous with age, the findings of the present study suggest that the influence of the home (as shown above with home availability) and of mother's food intake is important. Given that in the majority of households food shopping is predominantly undertaken by the mother ${ }^{(51)}$, nutrition interventions focusing on adolescents are unlikely to be effective if they do not also target mothers.

Perceived value of healthy eating was positively associated with the change in fruit consumption. The value (or reinforcing value) that adolescents place on certain behaviours can be described as the relative amount of motivated responding an individual is willing to engage in to gain access to one of two alternatives (e.g. fruit $v$. chocolate $)^{(52)}$. Research with adults has shown that the reinforcing value of certain foods is a stronger predictor of energy intake than liking of foods ${ }^{(53,54)}$. To the best of our knowledge, no previous study has examined the association between perceived value of healthy eating and the change in adolescent eating behaviours. A better understanding of how the reinforcing value of healthy eating develops as well as methods to make healthy foods more reinforcing may improve efforts to promote healthy eating to adolescents.

Support for healthy eating by best friends was positively associated with the change in vegetable consumption. This is a novel finding since there is a lack of longitudinal research examining the association between dietary behaviours and practices of friends during adolescence. That support for healthy eating by friends was associated with the change in vegetable consumption may be a reflection of the environments during which vegetables are consumed during adolescence (i.e. an option when eating out or at school mealtimes). Modelling of healthy eating by best friends was not associated with eating behaviours in the present study. This finding is consistent with that of previous studies ${ }^{(55,56)}$. Support for healthy eating by family and accessibility of places to buy fast foods and snacks close to home were not associated with the change in eating behaviours in the present study. Potentially, more direct or proximal factors (i.e. modelling by mother, availability of foods within, rather than around, the home) may be more important determinants of the change in eating behaviours for this target group, whose diets are still relatively heavily dependent on the purchasing decisions of the households' primary food provider.

In considering these findings, it is important to acknowledge the limitations of the study. There was some loss of participants at follow-up and some differences between those with follow-up data and those with baseline-only data, although the sample at follow-up remained diverse. A mixture of food-specific (e.g. self-efficacy for increasing fruit consumption) and more general (e.g. modelling of 
healthy eating) predictor variables was examined in relation to multiple dietary outcomes in the present study. Examining the associations between food-specific predictor variables and specific eating behaviours could be insightful; however, due to the nature of the YEP study, this was not possible. To overcome some of the challenges with the YEP study relating to participation rate, the original questionnaire was reduced after pilot testing to minimise respondent burden. Furthermore, the YEP study was designed to look at a range of dietary outcomes of which fruits, vegetables and energy-dense snacks are just three, so given the need to minimise the respondent burden as mentioned earlier, in most cases, it was not possible to include predictors specific to each dietary outcome. All data were collected by self-report and are subject to socially desirable response bias or other misreporting. When using observational data, prospective relationships can, as for cross-sectional data, be due to a third antecedent. Thus, we do not assume causality. Strengths of the study include its longitudinal design, the large regionally diverse sample of adolescents, the long time frame of follow-up and a range of theoretically derived predictors from individual, social and physical environmental domains.

Acknowledging its limitations, the findings of the present study are important since little is known about the mechanisms underlying dietary behavioural change among adolescents. The findings suggest that future study should assess the effectiveness of methods to increase self-efficacy for healthy eating and to improve home availability of healthy food options in programmes promoting healthy nutrition among adolescents. The involvement of mothers is likely to be particularly important in such efforts.

\section{Acknowledgements}

There are no conflicts of interest. The present study was funded by the Australian Research Council (DP0452044) and the William Buckland Foundation; the National Medical Research Council Senior Research Fellowship (479513 to K. B.); the VicHealth Senior Public Health Research Fellowship to D. C. The contribution of authors was as follows: N. P. carried out the statistical analyses and drafted the manuscript. K. B. and D. C. were involved in the design and in conducting the study and contributed to the drafting of the manuscript. All authors read and approved the final manuscript.

\section{References}

1. World Health Organisation (2003) Diet, Nutrition and the Prevention of Chronic Diseases: Report of a Joint WHO/ FAO Expert Consultation. WHO Technical Report Series no. 916. Geneva: WHO.

2. Lytle LA, Seifert S, Greenstein J, et al. (2000) How do children's eating patterns and food choices change over time?
Results from a cohort study. Am I Health Promot 14 , 222-228.

3. Colditz GA \& Frazier AL (1995) Models of breast cancer show that risk is set by events of early life: prevention efforts must shift focus. Cancer Epidemiol Biomarkers Prev 4, 567-571.

4. Maynard M, Gunnel D, Emmett P, et al. (2003) Fruit, vegetables and antioxidants in childhood and risk of adult cancer: the Boyd Orr cohort. J Epidemiol Commun Health 57, 218-225.

5. Larson NI, Neumark-Stzainer D, Hannan M, et al. (2007) Trends in adolescent fruit and vegetable consumption, 1999-2004 Project EAT. Am J Prev Med 32, 147-150.

6. Lien N, Lytle LA \& Klepp KI (2001) Stability in consumption of fruit, vegetables and sugary foods in a cohort from age 1421. Prev Med 33, 217-226.

7. Mikkila V, Rasanen L, Raitakari OT, et al. (2004) Longitudinal changes in diet from childhood into adulthood with respect to risk of cardiovascular diseases: The Cardiovascular Risk in Young Finns Study. Eur J Clin Nutr 58, 1038-1045.

8. Brug J, Oenema A \& Ferreira I (2005) Theory, evidence and intervention mapping to improve behaviour nutrition and physical activity interventions. Int J Behav Nutr Phys Act 2, 2.

9. McClain AD, Chappuis C, Nguyen-Rodriguez ST, et al. (2009) Psychosocial correlates of eating behavior in children and adolescents: a review. Int J Behav Nutr Phys Act 6, 54.

10. Shepherd J, Harden A, Rees R, et al. (2006) Young people and healthy eating: a systematic review of research on barriers and facilitators. Health Educ Res 21, 239-257.

11. Pearson N, Biddle SJH \& Gorely T (2008) Family correlates of fruit and vegetable consumption in children and adolescents: a systematic review. Pub Health Nutr 12, 267-283.

12. Rasmussen M, Krolner R, Klepp KI, et al. (2006) Determinants of fruit and vegetable consumption among children and adolescents: a review of the literature. Part I: quantitative studies. Int J Behav Nutr Phys Act 3, 22.

13. Boynton-Jarrett R, Thomas TN, Peterson KE, et al. (2003) Impact of television viewing patterns on fruit and vegetable consumption among adolescents. Pediatrics 112, 1321-1326.

14. Bere E \& Klepp KI (2005) Changes in accessibility and preferences predict children's future fruit and vegetable intake. Int J Behav Nutr Phys Act 2, 15.

15. Ezendam NPM, Evans AE, Stigler MH, et al. (2010) Cognitive and home environmental predictors of change in sugarsweetened beverage consumption among adolescents. Br J Nutr 103, 768-774.

16. Michie S \& Abraham C (2004) Interventions to change health behaviours: evidence-based or evidence inspired? Health Psychol 19, 29-49.

17. Glanz K \& Bishop DB (2010) The role of behavioral science theory in development and implementation of public health interventions. Annu Rev Pub Health 31, 399-418.

18. Cerin E, Barnett A \& Baranowski T (2009) Testing theories of dietary behavior change in youth using the mediating variable model with intervention programs. J Nutr Educ Behav 41, 309-318.

19. Ball K, Crawford D \& Mishra G (2006) Socio-economic inequalities in women's fruit and vegetable intakes: a multilevel study of individual, social and environmental mediators. Public Health Nutr 9, 623-630.

20. Davison KK \& Birch LL (2001) Childhood overweight: a contextual model and recommendations for future research. Obes Rev 2, 159-171.

21. Hume C, van der Horst K, Brug J, et al. (2010) Understanding the correlates of adolescents' TV viewing: a social ecological approach. Int J Pediatr Obes 5, 161-168. 
22. Norman GJ, Schmid BA, Sallis JF, et al. (2005) Psychosocial and environmental correlates of adolescent sedentary behaviors. Pediatrics 116, 908-916.

23. Sallis JF, Owen N \& Fisher EB (2002) Ecological models of health behavior. In Health Behavior and Health Education: Theory, Research and Practice [K Glanz, BK Rimer and FM Lewis, editors]. San Francisco, CA: Jossey-Boss.

24. McLeroy KR, Bibeau D, Steckler A, et al. (1988) An ecological perspective on health promotion programs. Health Educ $Q$ 15, 351-377.

25. MacFarlane A, Crawford D, Ball K, et al. (2007) Adolescent home food environments and socioeconomic position. Asia Pac J Clin Nutr 16, 748-756.

26. Savige GS, Ball K, Worsley A, et al. (2007) Food intake patterns among Australian adolescents. Asia Pac J Clin Nutr 16, $738-747$.

27. Neumark-Sztainer D, Wall M, Perry C, et al. (2003) Correlates of fruit and vegetable intake among adolescents. Findings from Project EAT. Prev Med 37, 198-208.

28. Marks GC, Webb K, Rutishauser IHE, et al. (2001) Monitoring Food Habits in the Australian Population Using Short Questions. Canberra: Commonwealth of Australia.

29. Willett W (1998) Nutritional Epidemiology. New York: Oxford University Press.

30. Mishra G, Ball K, Arbuckle J, et al. (2002) Dietary patterns of Australian adults and their association with socioeconomic status: results from the 1995 National Nutrition Survey. Eur J Clin Nutr 56, 687-693.

31. Sallis JF, Grossman RM, Pinski RB, et al. (1987) The development of scales to measure social support for diet and exercise behaviors. Prev Med 16, 825-836.

32. Twisk J \& Proper K (2004) Evaluation of the results of a randomized controlled trial: how to define changes between baseline and follow-up. J Clin Epidemiol 57, 223-228.

33. Bordo S (1990) Reading the slender body. In Body/ Politics: Women and the Discourses of Science, pp. 83-112 [M Jacobus, EF Keller and S Shuttleworth, editors]. New York: Routledge.

34. Lyman B (1982) The nutritional values and food group characteristics of foods preferred during various emotions. J Psychol 112, 121-127.

35. Baranowski T, Cullen KW \& Baranowski J (1999) Psychosocial correlates of dietary intake: advancing dietary intervention. Annu Rev Nutr 19, 17-40.

36. Pearson N, MacFarlane A, Crawford D, et al. (2009) Family circumstance and adolescent dietary behaviours. Appetite 52, 668-674.

37. Haerens L, Craeynest M, Deforche B, et al. (2008) The contribution of psychosocial and home environmental factors in explaining eating behaviours in adolescents. Eur J Clin Nutr 62, 51-59.

38. Hanson NI, Neumark-Sztainer D, Eisenberg ME, et al. (2005) Associations between parental report of the home food environment and adolescent intakes of fruits, vegetables and dairy foods. Public Health Nutr 8, 77-85.
39. Pearson N, Atkin AJ, Biddle SJ, et al. (2010) Parenting styles, family structure and adolescent dietary behaviour. Public Health Nutr 13, 1245-1253.

40. De Bourdeaudhuij I \& Van Oost P (2000) Personal and family determinants of dietary behaviour in adolescents and their parents. Psychol Health 15, 751.

41. Young EM, Fors SW \& Hayes DM (2004) Associations between perceived parent behaviors and middle school student fruit and vegetable consumption. J Nutr Educ Behav 36, $2-8$.

42. Ajzen I (1991) The theory of planned behavior. Organ Behav Hum Decis Process 50, 179-211.

43. Ajzen I (2002) Perceived behavioral control, self-efficacy, locus of control, and the theory of planned behavior. $J A p p l$ Soc Psychol 32, 665-683.

44. Cusatis DC \& Shannon BM (1996) Influences on adolescent eating behavior. $J$ Adolesc Health 18, 27-34.

45. Bandura A (1997) Self-efficacy: The Exercise of Control. New York: Freeman Press.

46. Baumrind D (1975) Early socialization and adolescent competence. In Adolescence in the Life Cycle: Psychological Change and Social Context: Psychological Change and Social Context [SE Dragastin and GH Elder, editors]. New York: Wiley.

47. Bandura A (1997) Self-efficacy in Changing Societies. Cambridge: Cambridge University Press.

48. Story M, Kaphingst KM, Robinson-O'Brien R, et al. (2008) Creating healthy food and eating environments: policy and environmental approaches. Annu Rev Pub Health 29, $253-272$.

49. French SA, Story M, Neumark-Sztainer D, et al. (2001) Fast food restaurant use among adolescents: associations with nutrient intake, food choices and behavioral and psychosocial variables. Int J Obes 25, 1823-1833.

50. Adair LS \& Popkin B (2005) Are child eating patterns being transformed globally? Obes Res 13, 1281-1299.

51. Bittman M (1995) Recent Changes in Unpaid Work. Canberra: Australian Bureau of Statistics.

52. Roemmich JN, Barkley JE, Lobarinas CL, et al. (2008) Association of liking and reinforcing value with children's physical activity. Physiol Behav 92, 1011-1018.

53. Epstein LH, Wright SM, Paluch RA, et al. (2004) Food hedonics and reinforcement as determinants of laboratory food intake in smokers. Physiol Behav 81, 511-517.

54. Epstein LH, Temple JL, Neaderhiser BJ, et al. (2007) Food reinforcement, the dopamine D2 receptor genotype, and energy intake in obese and nonobese humans. Behav Neurosci 121, 877-886.

55. Feunekes GI, de Graaf C, Meyboom S, et al. (1998) Food choice and fat intake of adolescents and adults: associations of intakes within social networks. Prev Med 27, 645-656.

56. Zabinski MF, Daly T, Norman GJ, et al. (2006) Psychosocial correlates of fruit, vegetable, and dietary fat intake among adolescent boys and girls. J Am Diet Assoc 106, 814-821. 